\title{
Study of Genetic Diversity in Upland Cotton (Gossypium hirsutum L.) of Cotton Leaf Curl Disease Resistant and Susceptible Genotypes by Using ISSRS
}

\author{
Sonika* and R.S. Sangwan \\ Department of Genetics and Plant Breeding, CCS, Haryana Agricultural University, \\ Hisar-125004, Haryana, India \\ *Corresponding author
}

\begin{abstract}
A B S T R A C T
Keywords

Agarose gel

electrophoresis,

Genetic diversity,

Genotypes, ISSR

primers,

Polymorphism

Article Info

Accepted:

07 February 2018

Available Online:

10 March 2018

Cotton is an important fiber cash crop of India and cotton leaf curl disease is the major biotic constraint that can significantly reduce the production and productivity of the crop. Gossypium hirsutum L. suffered losses in Northern part of India mainly in Haryana due to high incidence of cotton leaf curl disease (CLCuD) and "whitefly" which is the vector of this disease. Development of resistant variety to this disease is most effective, long term and safe method to tackle with this problem. First step in this direction is screening and identification of resistant sources and their incorporation in the agronomical superior genotypes/varieties. For this purpose, Genetic diversity between selected resistant (GCH 3 and $\mathrm{H} \mathrm{1353)}$ ) and susceptible (HS 6 and RST 9) parents to cotton leaf curl disease was studied in non-segregating generations i.e. $\mathrm{P}_{1}, \mathrm{P}_{2}$ and $\mathrm{F}_{1}$ generations of four G. hirsutum crosses. Twenty eight ISSR primers were used to generate DNA profile of parental genotypes and their $F_{1} s$ with a view to study polymorphism/ genetic diversity. Out of twenty eight ISSR primers, twenty one primers were found as polymorphic. A total of 175 alleles were amplified unambiguously by these 28 ISSR primers, of which 127 alleles were polymorphic (72.57 per cent) and ranged in size from 150-1000 bp. Inspite of per cent polymorphism, the primers showed remarkable polymorphic information content (PIC) values. The PIC value was found in the range of 0.495 to 0.907 . The ISSR primer UBC 834 was found to have maximum PIC value (0.907) and was found as more informative to be used in the early screening of the germplasm lines.
\end{abstract}

\section{Introduction}

Cotton is the leading and most important fiber cash crop of the world. India was the first country in the world to domesticate cotton for the production of cotton fabrics, when members of the Indus Valley Civilization began to grow the fiber in $1750 \mathrm{BC}$ for manufacturing textiles (Thomasson, 2010).
After China, India is the largest producer and consumer of cotton. Cotton as a crop as well as commodity plays an important role in the agrarian and industrial activity of the nation and has a unique place in the economy of our country. It is contributing about $65 \%$ of the raw material for the textile industry. Our economy is consistently influenced by cotton through its production, processing and by 
generating direct and indirect employment to more than eight million people. In India all the four cultivated species of cotton i.e. $G$. hirsutum, G. barbadense, G. arboretum and $G$. herbaceum are being grown. In North India, G. hirsutum and G. arboreum spp. are commercially cultivated. In this zone, low productivity of cotton is mainly due to high incidence of insect pests and diseases caused by fungal, bacterial and viral pathogens. Among the viral diseases cotton leaf curl disease $(\mathrm{CLCuD})$ is a major threat to the cotton production. During the year 2014-15 and 2015-16 upland cotton suffered losses even up to 100 per cent in some areas mainly due to high incidence of cotton leaf curl virus disease and "whitefly" which is the vector of this disease.

Use of chemicals in controlling this disease is not economic and also not so effective. Moreover, it may be hazardous to living beings and environment. Therefore, development of a resistant variety to this disease is the most effective, long term, less expensive and safe method to fight against this disease and to enhance and stabilize the productivity of cotton. Research efforts to develop resistant varieties/ hybrids through conventional/ biotechnological approaches along with cultural and management practices are in progress for effective control of this disease. The knowledge of genetic diversity in a crop species is fundamental to its improvement. Cotton improvement through conventional breeding is time consuming, the molecular markers offer a great opportunity for crop improvement as these are more reliable and can reduce time and money required for field-testing in crop improvement programs. DNA marker technology would provide a tool to the plant breeders to select desirable plants directly on the basis of genotype instead of the phenotype. The molecular marker techniques are fast and quick for the transfer of desirable genes from different varieties to the background of single genotype and also play role in the introgression of the novel genes from the related wild species into the local or popular genotypes which would then accelerate the process of the generation of new (improved) varieties.

It was reported by (Dahab et al., 2013) that the knowledge of genetic relationships among the plant genotypes helps to know about the complexity present in the available germplasm and also to discover the differences in available genotypes and to build up useful conservation plans for future work. Thus, evaluation based upon the molecular markers can provide the valuable insight into the genetic structure of a plant population, which helps in the development of new and improved varieties of the crop. This genetic diversity ensures protection procedures against diseases and pests and thus provides a basis for future genetic gains. The characterization of germplasm with molecular markers permits a more relevant choice of the resistant / tolerant genotype.

Molecular markers previously have been widely used in genetic analyses studies, breeding studies \& investigations of genetic diversity and the relationship between cultivated species and their wild parents. For the research involving cotton (Gossypium hirsutum L.), there are many genetic diversity studies which have been carried out in cotton by employing different molecular marker techniques such as amplified fragment length polymorphism (AFLP) (Abdalla et al., 2001; Rana et al., 2005; Li et al., 2008), random amplified polymorphic DNA (RAPD) (Xu et al., 2001; Chaudhary et al., 2010), Restriction Fragment Length Polymorphism (RFLP) and Simple Sequences Repeats (SSRs) (Qayyum et al., 2009; Arunita et al., 2010) but the major limitations of these methods are low reproducibility of RAPD and high cost \& use of radioactive probes in AFLP. 
In view of these limitations, ISSR-PCR is a technique that overcomes most of these limitations. ISSR is a PCR based simple, quick and efficient technique. It has high reproducibility and does not require radioactivity and it is useful in mapping and evolutionary biology in a wide range of crop species.

Work of (Khanam et al., 2012) suggested that ISSR markers allow the detection of the polymorphism in inter SSR loci using the primer (16 to $25 \mathrm{bp}$ long) complimentary to a single SSR and anneal at the either 3' or 5' end which can be di, tri, tetra or pentanucleotide as reported by (Reddy et al., 2002b).

This method provides highly reproducible results and generates abundant polymorphisms in many systems that's why it is quickly and rapidly being utilized by the research community in different areas of plant improvement such as in the studies of gene tagging, analysis of genetic diversity, and estimation of SSR motif as reported by (Blair et al., 1999; Bornet et al., 2002; Sica et al., 2005) thus more than one marker, likely to be promising for testing molecular variation between parents and checking their $\mathrm{F}_{1} \mathrm{~s}$. ISSRs have been reported as quite useful markers for revealing polymorphism in cotton genotypes by Liu and Wendel (2001).

Keeping in view the above, the present investigation was planned to study molecular variation of upland cotton (Gossypium hirsutum L.) genotypes through molecular markers with the following objectives. (1) To study molecular variation in different upland cotton genotypes using molecular marker (ISSR); (2) To find out the genetic relationship among different cotton genotypes and their $F_{1} s$ and (3) To know the degree of genetic divergence among different cotton genotypes (resistant and susceptible to cotton leaf curl disease).

\section{Materials and Methods}

The present investigation was conducted at cotton research station in collaboration with Department of (MBBB), CCS Haryana Agricultural University, Hisar, during 2015 and 2016.

\section{Plant material}

Four parents which included two resistant (GCH 3 and H 1353) and two susceptible (HS 6 and RST 9) to cotton leaf curl virus disease and their hybrids i.e. $\mathrm{F}_{1} \mathrm{~s}$ were taken for the present study. Four cotton genotypes that were used in this study are presented in Table 1. Young and actively growing leaves of cotton plants were used for DNA extraction.

\section{Development of breeding materials}

During Kharif 2013, the parents were identified from the germplasm and breeding material to fulfil the objectives. Among these parents GCH 3 and $\mathrm{H} 1353$ were identified as resistant whereas the parents RST 9 and HS 6 showed susceptible reaction to cotton leaf curl disease under field conditions and four $F_{1}$ crosses between these parents, namely $\mathrm{GCH} 3$, H 1353, RST 9 and HS 6 i.e. GCH 3 x HS 6 (R x S), GCH 3 x RST 9 (R x S), H 1353 x HS $6(\mathrm{R} \times \mathrm{S})$ and H $1353 \times \mathrm{RST} 9(\mathrm{R} \times \mathrm{S})$ were made. These crosses were designated as cross I, cross II, cross III and cross IV, respectively. The $F_{1}$ hybrids and parents were raised during kharif 2014. Each $\mathrm{F}_{1}$ was selfed to obtain $\mathrm{F}_{2}$ generation and simultaneously backcrossed to both of its parents to produce backcross generations $\left(\mathrm{BC}_{1}\right.$ and $\left.\mathrm{BC}_{2}\right)$. Fresh crosses were also made to obtain the $F_{1}$ seed and all the parents were selfed to get their seeds for the next year. The experimental material comprised of four crosses was grown in a randomized block design (RBD) with three replications during kharif, 2015 at Cotton Research Area, CCS Haryana Agricultural 
University, Hisar. There was a single row of non segregating generations i.e. $\mathrm{P}_{1}, \mathrm{P}_{2}$ and $\mathrm{F}_{1}$, 8 rows of $F_{2}$ and 4 rows of each back cross 1 and back cross 2 generations. In order to build up heavy inoculum pressure one row of highly susceptible line (HS 6) was planted at the periphery of the experimental area. Normal cultural practices were followed except insecticidal spray for control of white fly (Bemisia tabaci Genn.) population in the field. Reaction of cotton leaf curl virus disease was recorded on all the plants in all replications and the non segregating generations i.e. $\mathrm{P}_{1}, \mathrm{P}_{2}$ and $\mathrm{F}_{1} \mathrm{~s}$ of these four crosses were used as experimental material to collect leaf samples for the molecular study. The healthy as well as diseased leaves from the resistant and susceptible cotton genotypes and their respected $F_{1}$ hybrids of all the four crosses were collected and their DNA was isolated.

\section{DNA extraction}

Total genomic DNA was isolated following CTAB method modified by (Murray and Thompson, 1980). All DNA samples were given RNase treatment and were further purified.

\section{Qualitative and quantitative estimation of} DNA

The quantity and quality of DNA was checked by agarose gel $(0.8 \%)$ electrophoresis. The DNA was diluted to a final concentration of $25 \mathrm{ng} / \mu \mathrm{l}$. A single discrete band near the wells was observed in all genotypes (Fig. 1) showing that genomic DNA was intact, of high molecular weight and free from RNA contamination.

\section{Polymerase chain reaction (PCR) amplification}

Twenty eight random ISSR primers were screened to identify primers that were reproducible and generated the most polymorphic pattern. PCR reactions were carried out in Thermo Cycler in $10 \mu 1$ reaction mixture containing 1X PCR buffer, 5 per cent DMSO, $300 \mu \mathrm{M}$ dNTPs, $2.5 \mathrm{mM} \mathrm{Mgcl} 2,1 \mathrm{U}$ Taq DNA polymerase, $0.5 \mu \mathrm{M}$ primer (designed by Sigma- Aldrich Pvt. Limited, India) and DNA $25 \mathrm{ng}$. PCR cycles consisted of initial denaturation at $94^{\circ} \mathrm{C}$ for 5 min., 35 cycles of denaturation at $94^{0} \mathrm{C}$ for $35 \mathrm{sec}$., annealing (as mentioned in Table 2) for 1 min., extension at $72^{\circ} \mathrm{C}$ for $1 \mathrm{~min}$. and a final extension at $72^{\circ} \mathrm{C}$ for $10 \mathrm{~min}$. The amplification product $(10 \mu \mathrm{l})$ was electrophoressed on 1.5 per cent agarose gel in 1X TBE buffer and stained with ethidium bromide. Bands were visualized under UV transilluminator and photographed using Bio Rad Gel Documentation system.

\section{Molecular data analysis}

\section{Allele scoring}

The ISSR amplification profiles were scored by visual observations for parents and their $F_{1}$ generation. The presence of an amplified allele in each position was scored as 1 and the absence as 0 . The size (in nucleotides base pairs) of the amplified alleles was determined based on its migration relative to standard 100 bp DNA ladder.

\section{Polymorphic information content (PIC)}

Based on the frequency of allele for each primer, polymorphic information content (PIC) was calculated, using the following formula:

$\mathrm{PICi}=1-\sum_{j=1}^{n} P i j_{2}$

Where,

PICi is the polymorphic information content of a marker $i$, 
Pij is the frequency of the $\mathrm{j}^{\text {th }}$ pattern for marker i, and

The summation extends over $\mathrm{n}$ patterns

\section{Genetic similarity coefficient}

Based on the $0 / 1$ matrix of allele scoring, genetic similarity coefficient was calculated to estimate all pairwise differences in the amplification product for parents and their $F_{1}$ generation using 'SIMQUAL' sub-program of NTSYS-PC (version 2.02) software (Numerical Taxonomy and Multivariate Analysis System program) (Rohlf, 1997).

Similarity coefficients were then used for cluster analysis of parents and $\mathrm{F}_{1} \mathrm{~s}$ performed using the 'SAHN' (Sequential, Agglomerative, Heirarchial, Nested clustering method) sub-program of NTSYS-PC. Dendrogram was constructed by using distance matrix by the Unweighted Pair-Group Method with Arithmetic Average (UPGMA) sub-program of NTSYS-PC.

The data generated from polymorphic fragments were analyzed according to the formula given below:

Similarity Coefficient $=\frac{2 M x}{M y+M z}$

Dissimilarity $=1-\mathrm{F}$

Where,

$M x=$ Number of shared fragments between genotypes y and $\mathrm{z}$

My = Number of scored fragments of genotype y

$\mathrm{Mz}=$ Number of scored fragments of genotype $\mathrm{z}$
Principal component analysis (PCA) was done to construct two and three dimensional diagrams for providing suitable means of testing the relationship among parents and their $F_{1} s$ using the EIGEN vectors and values.

\section{Results and Discussion}

\section{Amplified product visualization}

The amplified PCR products, obtained through ISSRs were separated by $1.5 \%$ agarose gel electrophoresis and visualized under UV light. The amplification pattern of selected ISSRs is presented in Figure 2 (a-e). Some ISSR bands occured only in the susceptible genotypes of the four crosses (HS 6 and RST 9) like band no. 2 (500 bp) of ISSR 16 occurred only in susceptible genotypes and some ISSR bands occur only in the resistant genotypes of four crosses respectively.

Clearly resolved bands were scored. Molecular weights of the bands were estimated by using 100 bp DNA ladder as standards.

Genetic variation (polymorphism among) in parents and their $F_{1} S$ of four crosses using ISSR primers

Molecular markers have been widely used in genetic analyses, breeding studies and investigations of genetic diversity that ensures protection procedures against diseases and pests, and thus provide a base for future genetic gains (Esbroeck et al., 1998). Different molecular markers including RAPD (Random Amplified Polymorphic DNA) and AFLP (Amplified Fragment Length Polymorphism) have been used for studying genetic diversity and hybridization in cotton as reported by Kumar et al., (2003), VafaieTabar et al., (2003), Mehetre et al., (2004), Dongre et al., (2007), Preetha and Raveendren (2008), Wei et al., (2008), Tafvizei et al., 
(2010) but the major limitations of these methods are low reproducibility of RAPD and high cost \& use of radioactive probes in AFLP. ISSR-PCR is a technique that overcomes most of these limitations.

It is rapidly being used by the research community in various field of plant improvement (Reddy et al., 2002a) such as for the molecular studies of the genetic diversity.

In the present study, twenty eight ISSR primers used to generate DNA profile of parental genotypes and their F1s with a view to study genetic diversity. A total of 175 alleles were amplified unambiguously by the 28 ISSR primers, of which 127 alleles were polymorphic (72.57 per cent) and ranged in size from 150-1000 bp.

Out of 21 polymorphic ISSR primers, seven primers gave 100 per cent polymorphism, two primers gave 90.9 per cent polymorphism, four primers gave polymorphism between 8087.5 per cent, three primers gave polymorphism between $70-75$ per cent, two primers gave 60 per cent polymorphism, other two gave 50 per cent polymorphism, one primer gave 25 per cent polymorphism and seven primers were found monomorphic.

The mean percentage of polymorphism obtained with ISSR primers in the present study was found 72.57 per cent with a range of 0 per cent (17898 A, ISSR 10, ISSR 11, IS 15, UBC 811, UBC 827 and 844 A) to 100 per cent (ISSR 31, HB 08, HB 12, UBC 823, UBC 834, UBC 849 and 844 B). Similar study was also conducted in cotton by (Preetha and Raveendren, 2008), in which the mean percentage of polymorphism obtained with ISSR markers was 50.49 per cent, with a range of 0 per cent with (GA) 9A to 87 per cent with UBC 807. The highest values for PIC occurred with the UBC 807 primer (0.498), while the lowest values for the same parameters were observed with the (GA) 9A primer (0.0 per cent).

In present study total no. of alleles obtained with ISSR 1, UBC 807 and UBC 849 were 10, 11 and 6, respectively and PIC values obtained were 0.897 for ISSR $1,0.882$ for UBC 807 and 0.828 for UBC 849 . Similar results were obtained earlier in cotton by (Noormohammadi et al., 2013), in which, a total of 86 alleles were obtained from nine ISSR primers, out of which 54 showed 62.79 per cent polymorphisms and total no. of alleles obtained with ISSR 1 was 8, 12 with UBC 807 and 8 with UBC 849 and PIC values obtained for ISSR 1, UBC 807 and UBC 849 were $0.874,0.904$ and 0.878 , respectively.

Genetic relationship among parents and their $\mathrm{F}_{1} \mathrm{~S}$ using ISSR primers

Inspite of per cent polymorphism, the primers showed remarkable polymorphic information content (PIC) values. The data in Table 2, showed polymorphic information content (PIC) value for all the ISSR primers. The PIC value was found in the range of 0.495 to 0.907. In the present investigation 19 ISSR markers revealed PIC values of more than 0.75 indicating their usefulness in detecting polymorphism between the resistant and susceptible cotton genotypes. The ISSR primer UBC 834 was found to have maximum PIC value (0.907) followed by ISSR1 with PIC value of 0.897 and minimum PIC value (0.495) was found for IS15. This highest value might be the result of diverse parental genotypes and their $\mathrm{F}_{1} \mathrm{~s}$ with maximum number of alleles (13) while lowest PIC value (0.495) for IS 15 may be the result of closely related genotypes with two alleles. Clearly, it can be stated that, the ISSR primer UBC 834 with greater numbers of alleles tend to have higher PIC values and thus may be more informative. 
Table.1 Cotton (Gossypium hirsutum L.) genotypes used in the present study

\begin{tabular}{|c|l|l|}
\hline No. & Genotype & Source \\
\hline 1. & GCH 3 & CCS HAU Hisar \\
\hline 2. & H 1353 & CCS HAU Hisar \\
\hline 3. & HS 6 & CCS HAU Hisar \\
\hline 4. & RST 9 & ZARS RAU Rajasthan \\
\hline
\end{tabular}

Table.2 DNA polymorphism in four cotton parents and their $\mathrm{F}_{1} \mathrm{~s}$ using twenty eight ISSR primers

\begin{tabular}{|c|c|c|c|c|c|c|c|c|}
\hline $\begin{array}{l}\text { No } \\
\text { • }\end{array}$ & Primer & Sequence (5’-3') & $\begin{array}{l}\text { Band } \\
\text { size (bp) }\end{array}$ & $\begin{array}{l}\text { Total no. } \\
\text { of alleles }\end{array}$ & $\begin{array}{l}\text { No. of } \\
\text { monomorph } \\
\text { ic alleles }\end{array}$ & $\begin{array}{l}\text { No. of } \\
\text { polymorph } \\
\text { ic alleles }\end{array}$ & $\begin{array}{l}\% \\
\text { polymorphi } \\
\text { sm }\end{array}$ & $\begin{array}{l}\text { PIC } \\
\text { value }\end{array}$ \\
\hline 1. & ISSR 1 & AGACAGACGC & $200-800$ & 10 & 3 & 7 & 70.0 & 0.897 \\
\hline 2. & ISSR 14 & CACACACACACAGT & $530-950$ & 6 & 1 & 5 & 83.0 & 0.790 \\
\hline 3. & ISSR 16 & CACACACACACAAG & $400-950$ & 12 & 3 & 9 & 75.0 & 0.888 \\
\hline 4. & ISSR 24 & GACAGACAGACAGACA & $600-890$ & 4 & 3 & 1 & 25.0 & 0.728 \\
\hline 5. & ISSR 31 & GAGGAGGAGGC & $270-900$ & 7 & 0 & 7 & 100.0 & 0.841 \\
\hline 6. & HB 08 & GAGAGAGAGAGAGG & $300-710$ & 5 & 0 & 5 & 100.0 & 0.778 \\
\hline 7. & HB 10 & GAGAGAGAGAGACC & $250-900$ & 6 & 1 & 5 & 83.3 & 0.824 \\
\hline 8. & HB 12 & CACCACCACGC & $170-700$ & 9 & 0 & 9 & 100.0 & 0.842 \\
\hline 9. & $17898 \mathrm{~A}$ & CACACACACACAAC & $700-900$ & 4 & 4 & 0 & 0 & 0.750 \\
\hline 10. & ISSR & CACACACACACACAGT & $\begin{array}{l}500- \\
1000\end{array}$ & 3 & 3 & 0 & 0 & 0.551 \\
\hline 11. & ISSR & GAGAGAGAGAGAGAGAGC & $\begin{array}{l}450- \\
1000\end{array}$ & 2 & 2 & 0 & 0 & 0.50 \\
\hline 12. & IS 5 & CACACACACACAAT & $350-900$ & 4 & 2 & 2 & 50.0 & 0.720 \\
\hline 13. & IS 15 & GTGTGTGTGTGTAT & $350-470$ & 2 & 2 & 0 & 0 & 0.495 \\
\hline 14. & UBC807 & AGAGAGAGAGAGAGAGT & $\begin{array}{l}350- \\
1000\end{array}$ & 11 & 1 & 10 & 90.9 & 0.882 \\
\hline 15. & UBC 808 & AGAGAGAGAGAGAGAGC & $400-900$ & 8 & 1 & 7 & 87.5 & 0.851 \\
\hline 16. & UBC 809 & AGAGAGAGAGAGAGAGG & $150-500$ & 5 & 2 & 3 & 60.0 & 0.792 \\
\hline 17. & UBC 810 & GAGAGAGAGAGAGAGAT & $\begin{array}{l}300- \\
1000\end{array}$ & 11 & 3 & 8 & 72.0 & 0.881 \\
\hline 18. & UBC 811 & GAGAGAGAGAGAGAGAC & $200-450$ & 3 & 3 & 0 & 0 & 0.663 \\
\hline 19. & UBC 816 & CACACACACACACACAT & $\begin{array}{l}900- \\
1000\end{array}$ & 5 & 1 & 4 & 80.0 & 0.748 \\
\hline 20. & UBC 823 & ТСТСТСТСТСТСТСТСС & $350-900$ & 8 & 0 & 8 & 100.0 & 0.863 \\
\hline 21. & UBC 825 & ACACACACACACACACT & $450-950$ & 5 & 2 & 3 & 60.0 & 0.794 \\
\hline 22. & UBC 827 & ACACACACACACACACG & $600-900$ & 3 & 3 & 0 & 0 & 0.612 \\
\hline 23. & UBC 834 & AGAGAGAGAGAGAGAGYT & $\begin{array}{l}300- \\
1000\end{array}$ & 13 & 2 & 11 & 100.0 & 0.907 \\
\hline 24. & UBC 840 & GAGAGAGAGAGAGAGAYT & $250-900$ & 11 & 1 & 10 & 90.9 & 0.877 \\
\hline 25. & UBC841 & GAGAGAGAGAGAGAGAYC & $300-700$ & 4 & 2 & 2 & 50.0 & 0.747 \\
\hline 26. & UBC 849 & GTGTGTGTGTGTGTGTYA & $500-800$ & 6 & 0 & 6 & 100.0 & 0.828 \\
\hline 27. & $844 \mathrm{~A}$ & СТСТСТСТСТСТСТСТАС & $350-700$ & 3 & 3 & 0 & 0 & 0.609 \\
\hline 28. & $844 \mathrm{~B}$ & СТСТСТСТСТСТСТСТGC & $350-800$ & 5 & 0 & 5 & 100.0 & 0.752 \\
\hline
\end{tabular}


Fig.1 Isolated and RNase treated genomic DNA samples run on $0.8 \%$ agarose gel

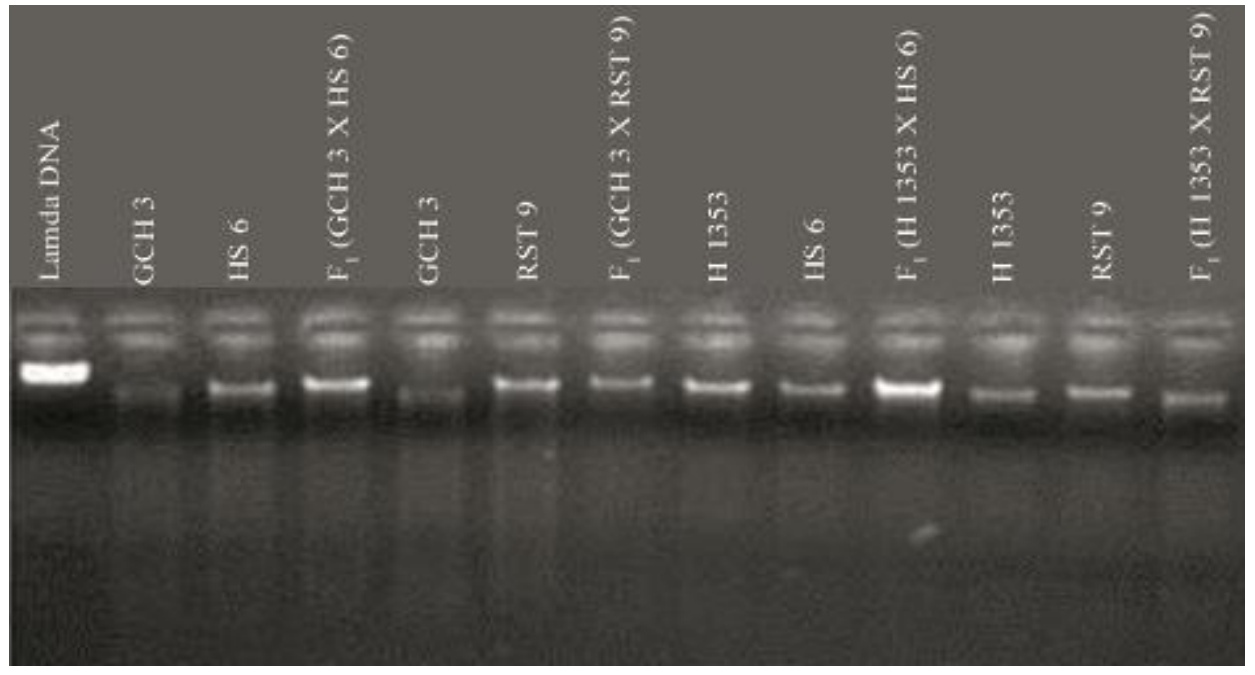

Fig.2 (a-e) Agarose gel electrophoresis pattern of PCR amplified products of parents and their $\mathrm{F}_{1} \mathrm{~s}$, using primers ISSR 16, UBC 840, UBC 823, HB10 and UBC 849

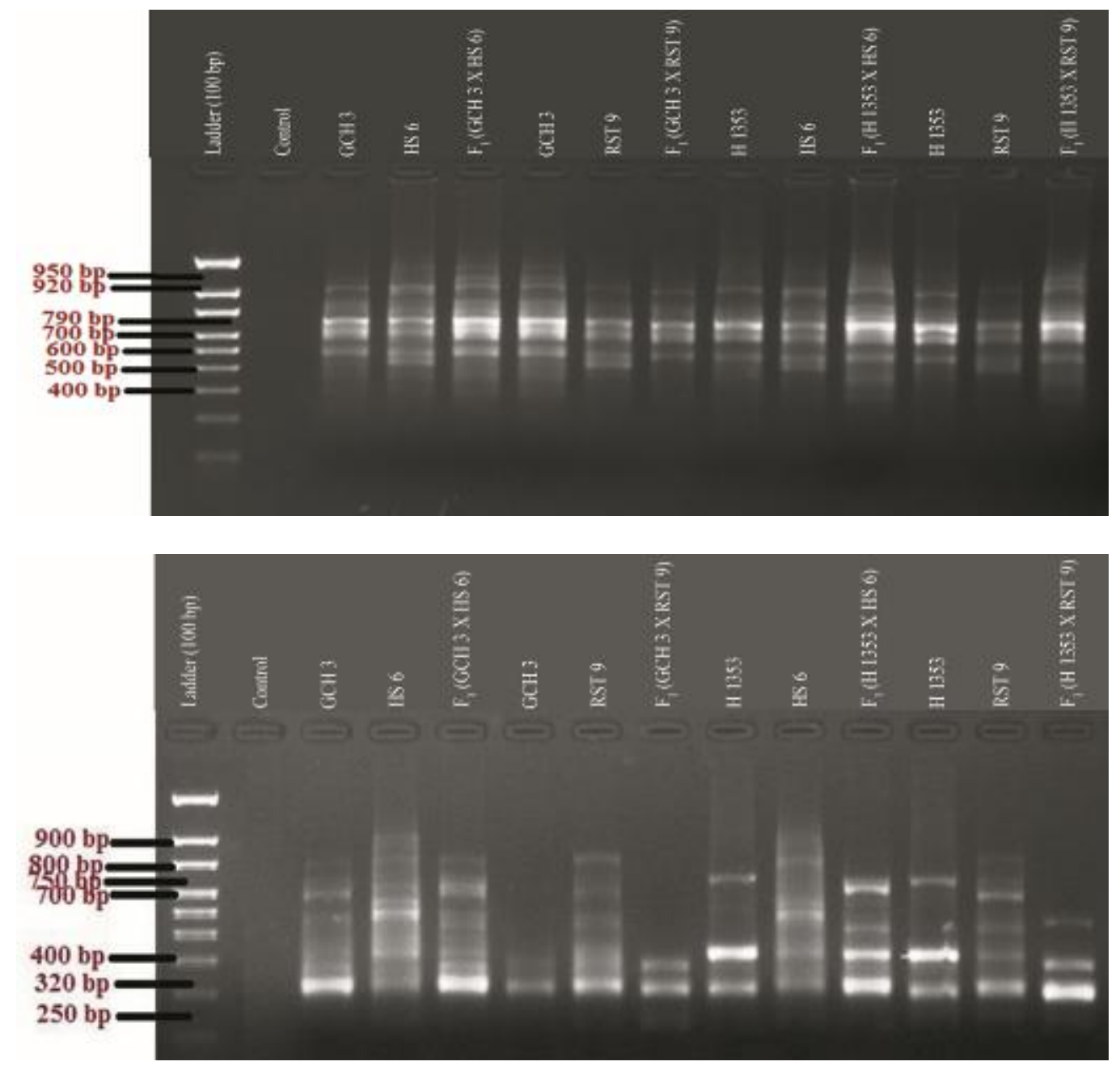



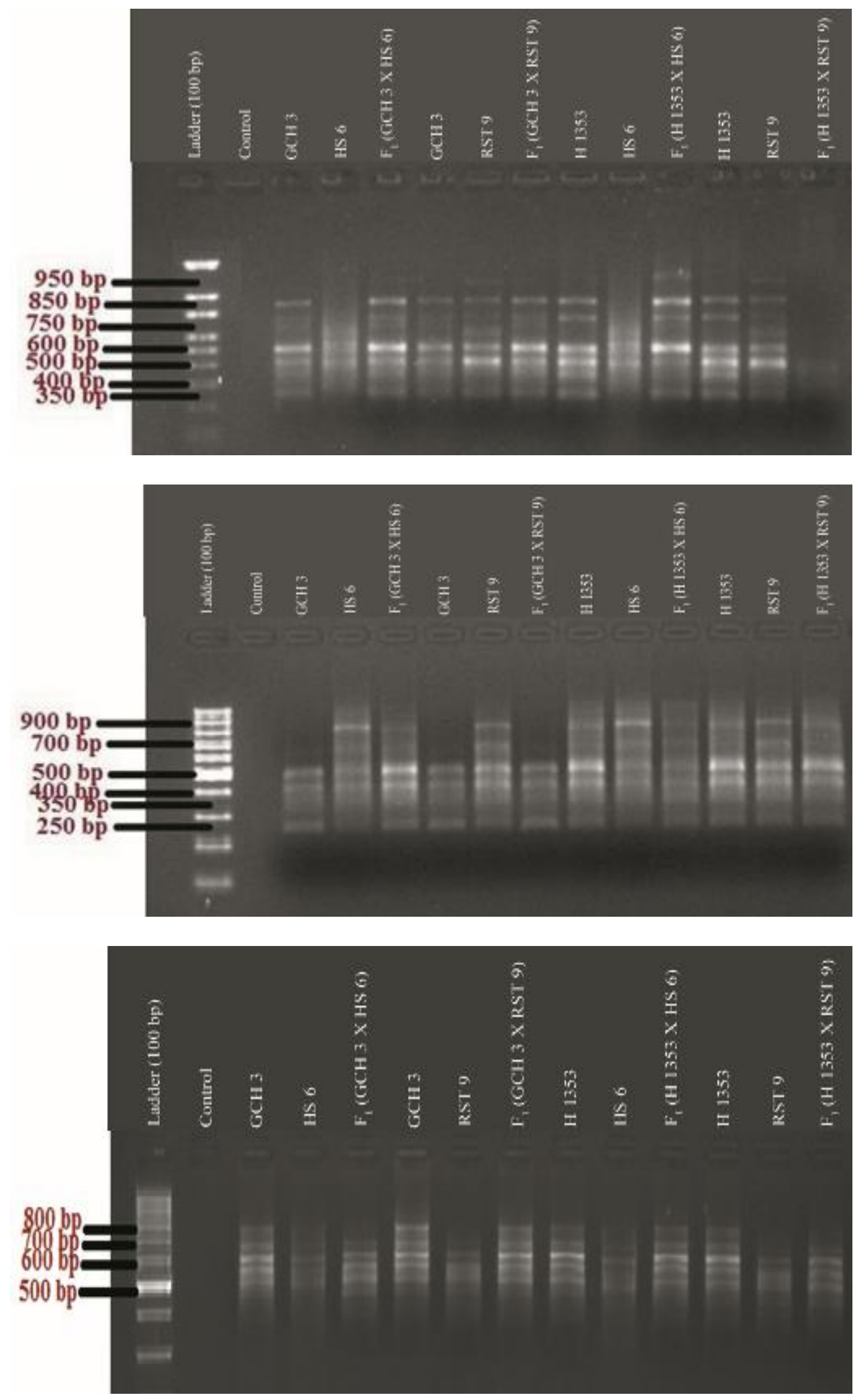
Fig.3 Dendrogram showing genetic diversity among selected parents and their $\mathrm{F}_{1} \mathrm{~s}$ using ISSR primers

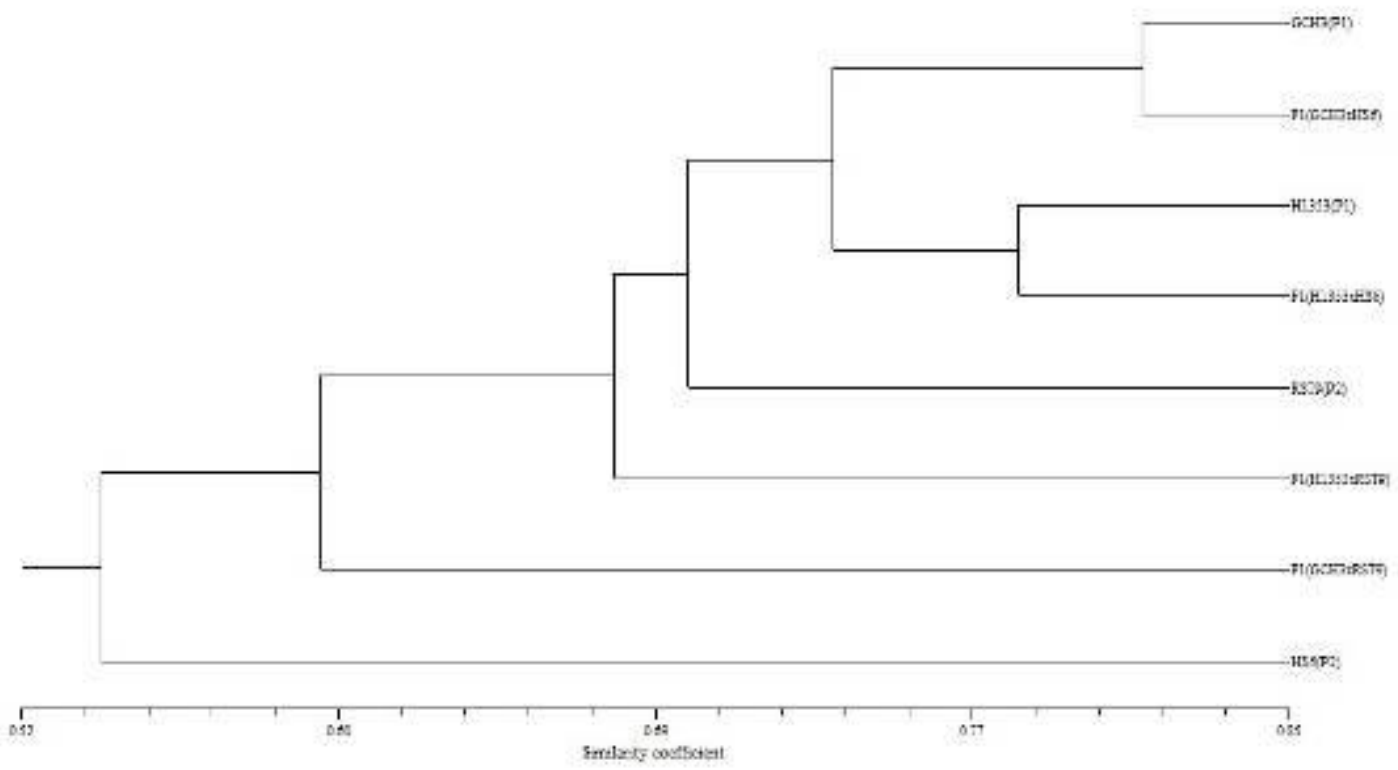

Fig.4 Two dimensional PCA (Principal component analysis) scaling of selected parents and their $\mathrm{F}_{1} \mathrm{~s}$ using 28 ISSR primers

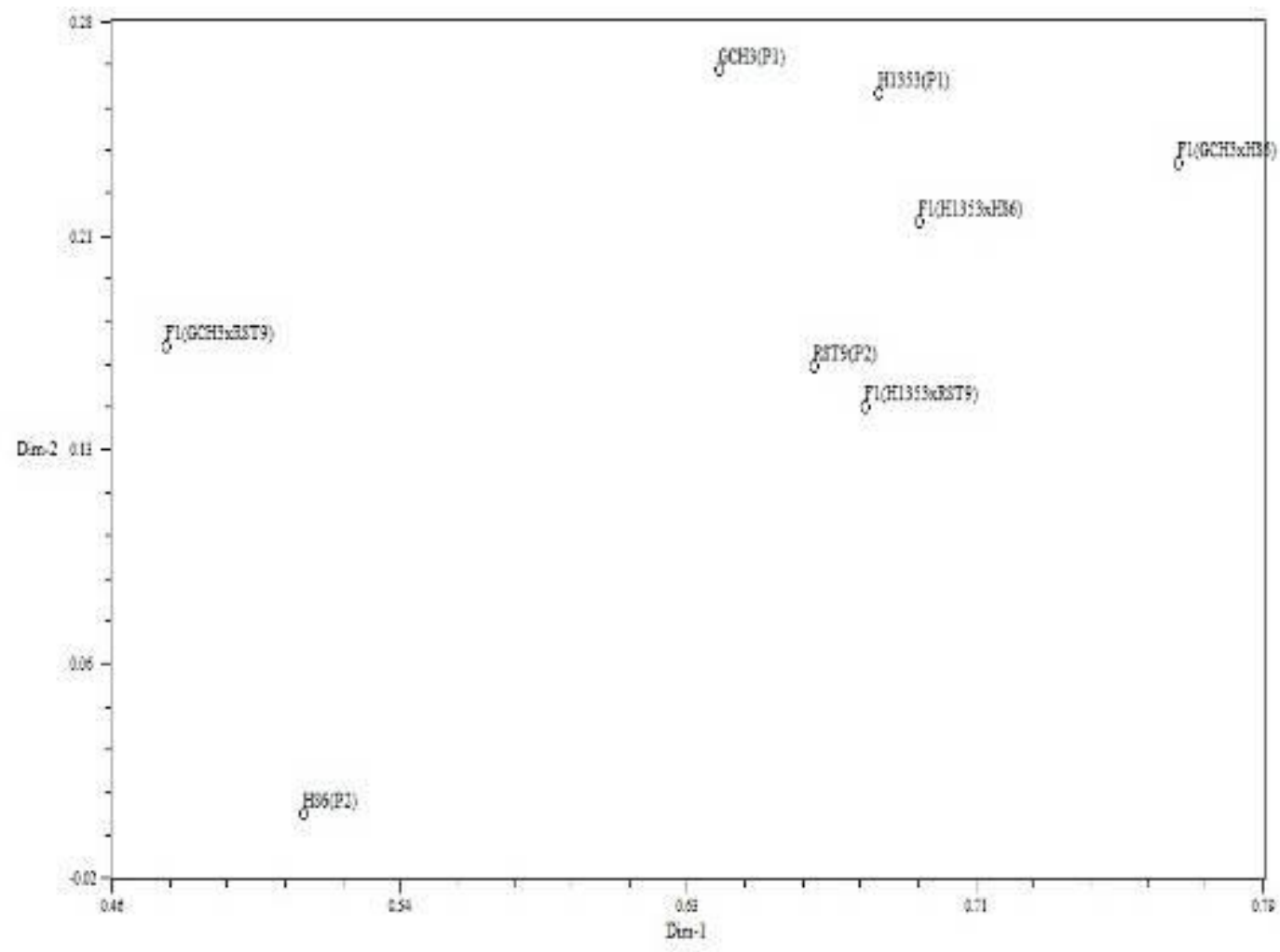


Fig.5 Three dimensional PCA scaling of parents and their $\mathrm{F}_{1} \mathrm{~s}$ using 28 ISSR primers

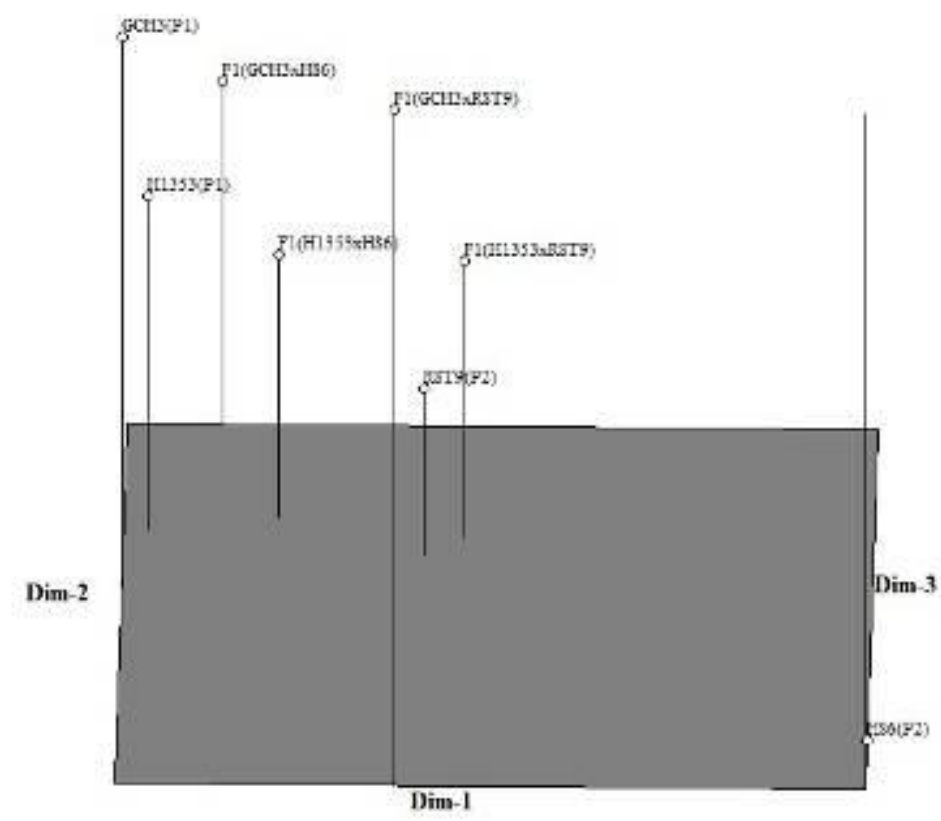

Out of all the primers, UBC 834 is the best primer that can be further used for the early screening of the germplasm lines as it showed high polymorphism between resistant and susceptible cotton genotypes and also it had highest PIC value (0.907).

\section{UPGMA cluster tree analysis}

The alleles scored in the binary matrix were used for calculation of similarity coefficient among the genotypes and construction of dendrogram using 'SIMQUAL' subprogramme of NTSYS-PC (version 2.02) software (Numerical Taxonomy and Multivariate Analysis System Programme). The association among the different parents and their $F_{1} S$ is presented in the form of dendrogram in Figure 3. The UPGMA cluster tree analysis led to the grouping of parents GCH 3, H 1353, HS 6 and RST 9 and their $\mathrm{F}_{1} \mathrm{~s}$ into two major groups at similarity index of $0.54-0.85$.

The similarity coefficient range obtained in this study is supported by the earlier genetic diversity studies in cotton, in which range was found from 0.53 to 0.88 as reported by (Noormohammadi et al., 2011). Present genetic diversity study by using ISSRs, resulted similarity coefficient from 0.54 to 0.85 which fills the similarity window between cotton genotypes that was observed in earlier studies that showed similarity coefficient range from 0.185 to 0.881 as reported by Kahodariya et al., (2015) and 0.77 to 0.97 as reported by Ashraf et al., (2016).

The dendrogram indicated that parents and their $F_{1} s$ of four crosses bifurcated at similarity coefficient of 0.54 and formed two major clusters A and B. At the same similarity coefficient, parent HS 6 was clustered separately. Cluster B was further differentiated into different sub-clusters at similarity coefficient of 0.60 . Similar cluster membership was found in another study of cotton by Parkhiya et al., (2014) in which cluster I included only one genotype and while cluster II consisted of rest of the genotypes grouped together in their respective 
sub-clusters. The parent HS 6 and $\mathrm{F}_{1} \mathrm{~s}$ of cross GCH 3 \& RST 9 and H 1353 and RST 9 is on the lower side of the dendrogram and as we move on the upper side of the dendrogram presence of parent $\mathrm{GCH} 3, \mathrm{H} 1353$ and $\mathrm{F}_{1} \mathrm{~s}$ of GCH 3 \& HS 6 and H 1353 and HS 6 was depicted. As depicted by dendrogram parent GCH 3 and parent HS 6 were found to be more divergent at similarity coefficient of 0.54 .

\section{Principal component analysis (PCA)}

The two-dimensional (Fig. 4) and threedimensional (Fig. 5) (PCA) Principal Component Analysis was done for providing suitable means of testing the relationship among four cotton genotypes and their $F_{1} s$ using the EIGEN programme NTSYS-PC. These plots also showed the similar results as that of dendrogram.

\section{Acknowledgements}

The author gratefully acknowledge the timely help, facilities and guidance provided by Dr. Somveer Nimbal from the cotton section, Department of Genetics and Plant Breeding, Dr. V. K. Sikka from Department of Molecular Biology Biotechnology and Bioinformatics, CCS Haryana Agricultural University, Hisar to complete the present investigation.

\section{Abbreviations}

CLCuD: Cotton leaf curl disease ISSR: Inter simple sequence repeat PIC: Polymorphic information content PCA: Principal component analysis

\section{References}

Abdalla, A., O. Reddy, K. El-Zik, A. Pepper; Genetic diversity and relationships of diploid and tetraploid cottons revealed using AFLP, Theor. Appl. Genet., 102, 222-229 (2001).
Arunita, R., S. Rakshit, V. Santhy, V.P. Gotmare, P. Mohan, V.V. Singh, S. Singh, J. Singh, H.S. Balyan, P.K. Gupta, S.R. Bhat; Evaluation of SSR markers for the assessment of genetic diversity and fingerprinting of Gossypium hirsutum accessions. J. Plant. Biochem. Biotechnol., 19, 153-160 (2010).

Ashraf, J., W. Malik, M.Z. Iqbal, A.A. Khan, A. Qayyum; Comparative analysis of genetic diversity among $B t$ cotton genotypes using ESTSSR, ISSR and morphological markers, J. Agri. Sci. Tech., 18, 517-531 (2016).

Blair, M.W., O. Panaud, S.R. McCouch, Intersimple sequences repeat (ISSR) amplification for analysis of microsatellite motif frequency and fingerprinting in rice (Oryza sativa L.). Theor. Appl. Genetics., 98(5), 780-792 (1999).

Bornet, B., C. Muller, F. Paulus, M. Branchard; Highly informative nature of inter simple sequence repeat (ISSR) sequences amplified using tri- and tetra-nucleotide primers from DNA of cauliflower (Brassica oleraceavar. botrytis L.). Genome, 45(5), 890-896 (2002).

Chaudhary, L., A. Sindhu, M. Kumar, R. Kumar, M. Saini; Estimation of genetic divergence among some cotton varieties by RAPD analysis.J. Plant. Breed. Crop. Sci., 2, 39-43 (2010).

Dahab, A.A., M. Saeed, B. B. Mohamed; Genetic diversity assessment of cotton (Gossypium hirsutum L.) genotypes from Pakistan using simple sequence repeat marker. Aust. J. Crop Sci., 7(2), 261-267 (2013).

Dongre, A.B., M. Bhandarkar, S.H. Banerjee; Genetic diversity in tetraploid and diploid cotton (Gossypium spp.) using ISSR and microsatellite DNA markers, Ind. J. Biotech., 6, 349-353 (2007).

Esbroeck, V. G. A., D. T. Bowman, D. S. Calhoun, O.L. May; Changes in the genetic diversity of cotton in the USA from 1970 to 1995, Crop Sci., 38, 33-37 (1998).

Kahodariya, J., P. Sabara, D. Vakharia; Assessment of genetic diversity in old world and new world cotton cultivars using RAPD and ISSR markers, Ind. J. Biotech., 14, 511-517 (2015).

Khanam, S.A., J. L. Sham, Bennetzen, M. A. M. Aly; Analysis of molecular marker based characterization and genetic variation in date palm (Phoenix dactylifera L.). Aust. J. Crop Sci., 6(8), 1236-1244 (2012).

Kumar, P., K. Singh, Y. Vikal, L. S. Randhawa, G. S. Chahal; Genetic diversity studies of elite cotton germplasm lines using RAPD markers 
and morphological characteristics, Ind. J. Genet., 63, 5-10 (2003).

Li, Z., X. Wang, Y. Zhang, G. Zhang, L. Wu, J. Chi, Z. Ma; Assessment of genetic diversity in glandless cotton germplasm resources by using agronomic traits and molecular markers. Front. Agric. Chin., 2, 245-252 (2008).

Liu, B., and J. F. Wendel; Inter simple sequence repeat (ISSR) polymorphisms as a genetic marker system in cotton.Mol. Ecol. Notes., 1, 205-208 (2001).

Mehetre, S.S., M. Gomes, S. Eapen; RAPD analysis of hybrid nature of the offspring of Gossypium hirsutum $x$ G. raimondii, Curr. Sci., 87, 25-28 (2004).

Murray, H.G., and W. F. Thompson; Rapid isolation of higher molecular weight DNA, Nuc. Acids.Res., 8, 4321-4325 (1980).

Noormohammadi, Z., M. H. Shamee, M. Sheidai, O. Alishah; The comparison of inter simple sequence repeat and randomly amplified polymorphic DNA markers for genetic assessment of intra-specific cotton hybrid genotypes, Geneconserve., 42, 270-292 (2011).

Noormohammadi, Z., Y. Farahani, M. Sheidai, S. Ghasemzadeh-Baraki, O. Alishah; Genetic diversity analysis in opal cotton hybrids based on SSR, ISSR, and RAPD markers, Genet. Mol. Res., 12(1), 256-269 (2013).

Parkhiya, S., K. Gohel, D. R. Mehta; Genetic diversity analysis of cotton (Gossypium hirsutum L.) genotypes using ISSR markers, Int. J. App. Pure Sci. Agri., 1, (1) (2014).

Preetha, S., and T. S. Raveendren; Molecular marker technology in Cotton, Biotech. Mol. Biol. Rev., 3, 032-045 (2008).

Qayyum, A., N. Murtaza, F. M. Azhar, W. Malik; Biodiversity and nature of gene action for oil and protein contents in Gossypium hirsutum L. Estimated by SSR markers. J. Food Agric. Environ., 7, 590-593 (2009).

Rana, M.K., V. P. Singh, K. V. Bhat; Assessment of genetic diversity in upland cotton (Gossypium hirsutum L.) breeding lines by using amplified fragment length polymorphism (AFLP) markers and morphological characteristics. Genet. Resour. Crop Evol., 52, 989-997 (2005).

Reddy, M.P., N. Sarla, E. A. Siddiq; Inter simple sequence repeat (ISSR) polymorphism and its application in plant breeding. Euphytica., 128(1), 9-17 (2002b).

Reddy, M.P., N. Sarla, E. A. Siddiq; Inter-simple sequence repeat (ISSR) polymorphism and its application in plant breeding, Euphytica., 128, 912 (2002a).

Rohlf, F.J. NTSYS-PC numerical taxonomy and multivariate analysis system, Exeter Software, (1997).

Sica, M., G. Gamba, S. Montieri, L. Gaudio, S. Aceto; ISSR markers show differentiation among Italian populations of Asparagus acutifolius L. BMC Genet.,6, article 17 (2005).

Tafvizei, F., M. Sheidai, Z. Nourmohammadi, O. Alishah, F. Farahani; Cytogenetic and RAPD analysis of cotton cultivars and their $F_{1}$ progenies, Caryolog, 63, 73-81 (2010).

Thomasson, S.C. Associate Editor, Textile World Asia, India: A Cotton Giant, India is a major player in the world cotton market. July / August / September, 2010.

Vafaie-Tabar, M., S. Chandrashekaran, R. P. Singh, M. K. Rana; Evaluation of genetic diversity in Indian tetraploid and diploid cotton (Gossypium spp.) by morphological characteristics and RAPDs, Ind. J. Genet., 63, 230-234 (2003).

Wei, J., Z. Hong-bo, H. Jue-min; Genetic diversity in germplasm resources of cotton from different area based on ISSR markers, Cotton Sci., 20, 348-353 (2008).

Xu, Q.H., X. L. Zhang, Y. C. Nie; Genetic diversity evaluation of cultivars ( $G$. hirsutum L.) from the Changjiang river valley and Tellow river valley by RAPD markers. Acta. Genet. Sin., 28, 683690 (2001).

\section{How to cite this article:}

Sonika and Sangwan, R.S. 2018. Study of Genetic Diversity in Upland Cotton (Gossypium hirsutum L.) of Cotton Leaf Curl Disease Resistant and Susceptible Genotypes by Using ISSRS. Int.J.Curr.Microbiol.App.Sci. 7(03): 570-582.

doi: https://doi.org/10.20546/ijcmas.2018.703.068 